IJBPAS, March, 2019, 8(3): 539-548

ISSN: $2277-4998$

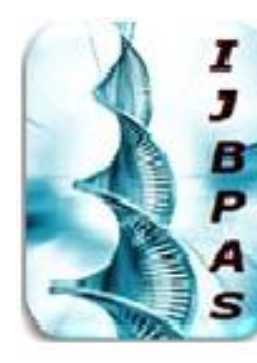

International Journal of Biology, Pharmaey and Allied Sciences (IJBPAS)

'A Bridge Between Caboratory and QRendo'

Www.iibpas.com

PREVALENCE OF AND FACTORS ASSOCIATED WITH TOBACCO USE AMONG

MALE MEDICAL UNDERGRADUATE STUDENTS IN RIYADH - A CROSS-

SECTIONAL STUDY

\title{
MAHMOUD ABDULRAHMAN MAHMOUD
}

Assistant professor of Community Medicine, Public Health Department, College of Medicine, Al Imam Mohammad Ibn Saud Islamic University, Riyadh, Kingdom of Saudi Arabia

*Corresponding Author: E Mail: communitydr@hotmail.com; Mobile: +966504699931

Received $11^{\text {th }}$ Oct. 2018; Revised $10^{\text {th }}$ Nov. 2018; Accepted $21^{\text {st }}$ Nov. 2018; Available online $1^{\text {st }}$ March 2019

https://doi.org/10.31032/IJBPAS/2019/8.3.4662

\begin{abstract}
Background: Tobacco use is one of the most important risk factors for non-communicable diseases. Health professionals such as medical students are vital agents of change in the fight against tobacco. The aim of this study was to estimate the prevalence of tobacco use and determine its associated factors among medical undergraduate students in a medical college in Riyadh city.
\end{abstract}

Methods: A college-based study was conducted in a medical university in Riyadh city using a convenient sampling method to achieve the required sample size of 215. A semi-structured pretested questionnaire was used to collect data on tobacco use by the participants, their parents and siblings, and other socio-demographic details. Ethical clearance was taken from institute ethics committee.

Result: Majority of the students were 20-21 years old, belonged to middle-income families and had well-educated parents. The prevalence of current tobacco use was $22.8 \%$ and among them $98 \%$ were current smokers. Siblings' smoking status was significantly associated with tobacco use. 
Conclusion: Tobacco cessation counseling and tobacco use prevention activities should be incorporated in the medical curriculum.

\section{Keywords: prevalence, tobacco, smoking, college students, medical students, Riyadh INTRODUCTION}

Tobacco use is one of the most important risk factors for mortality and morbidity due to non-communicable diseases. According to the World Health Organization (WHO), tobacco accounts for about six million deaths globally which is almost $6 \%$ of all female and $12 \%$ of all male deaths (1). According to 2013 Saudi Health Information Survey, among adults aged $>15$ years, $24 \%$ of men and $1.5 \%$ women were current tobacco smokers and this proportion was found to be higher in the younger population (2). Although laws related to tobacco remain in place and Saudi Arabia became a signatory to the Framework convection on Tobacco Control (FCTC) in 2007, there were no significant reductions in the prevalence of tobacco use over the years (3). Saudi Arabia is experiencing a huge tobacco problem and the government is currently exploring its options to control the tobacco epidemic.

Health professionals play a key role in the tobacco cessation efforts, starting from providing counseling and behavioral therapy in the clinic rooms to setting a role model in the community (4). WHO also emphasizes the role of health professionals in tobacco control (4). Tobacco use among medical professionals not only affects their own health but also has a wider social impact. Consumption of tobacco by health professional in any form may hamper the process of tobacco control among general population. According to Global Health Professional Survey (GHPS) conducted in 2005 among the health professionals in ten countries, seven showed more than 20\% prevalence (5). The WHO advocates periodic surveys among adults and youth as they are important for tracking and implementation of tobacco control interventions $(6,7)$. Similarly, periodic tobacco use surveillance among health professionals will also help us to determine the trends among the health professionals.

In keeping with the above concerns, this study was conducted to estimate the prevalence of tobacco use and its associated factors among medical undergraduate students of a medical university in Riyadh city.

\section{METHODS}

This study was a college-based cross sectional survey conducted in 2016, among 
medical undergraduate students of a medical university in Riyadh city. Sample size was calculated for an expected tobacco use prevalence of $18.6 \%$, an absolute precision of $6 \%$ and a non-response rate of $25 \%(8)$. The final sample size came out to be 215. A convenient sample of students currently pursuing their medical under-graduation course was included in the study till the required sample size was achieved. The inclusion criterion was male students aged 18 years or more. All consenting participants were given a pretested semi-structured questionnaire to fill. Apart from tobacco use data, questions were asked about sociodemographic characteristics, year of study, average grade points, perceptions about effects of tobacco, parent's educational and smoking status and sibling's smoking status.

Ethical approval was taken from the institute ethics committee and informed consent was taken from all the participants. Confidentiality of collected information and other ethical principles were maintained according to the 1964 Helsinki declaration.

\section{Statistical analysis}

Data were entered using Microsoft excel and data analysis was done using STATA 12. Descriptive analysis was done for sociodemographic factors and prevalence of tobacco use. Chi square test was used to test differences in prevalence according to the various proposed socio-demographic and other factors. Logistic regression was used to determine the factors that were significantly associated with tobacco use.

\section{RESULTS}

\section{Socio-demographic Characteristics}

Majority of the participants belonged to the age group of 20-21 years, followed by those in the age group of 22-23 years. The students were almost equally distributed across the various years of the course. About $75 \%$ of the participants rated themselves to be in the middle-income socio-economic status. Majority of the participants had mothers and fathers who were educated till college. Only $12 \%$ of the participants were living alone away from their family and the others were living with their families. About half (50.7\%) of the students had a grade point average of 3.01 to 4.00 (Table 1 ).

\section{Tobacco consumption}

About 23\% of the participants said that they currently used tobacco in any form. Among tobacco users, $98 \%$ were current cigarette smokers whereas $2 \%$ reported tobacco chewing currently. Among the smokers, a large majority (73\%) smoked daily and half of those smoked 10 or more cigarettes per day. Majority (48\%) of the current smokers started smoking at 16 to 18 years of age. 
About $85 \%$ of the current smokers had thought about quitting in the past year. Majority of the participants (41\%) said they first got the idea of smoking at school and $14 \%$ reported media as the source of such information. Nearly all the students (97\%) believed that smoking was harmful for health. When asked about tobacco use in the family members, $21 \%$ said that their father smoked, $3 \%$ said that their mother smoked and $24 \%$ said that at least one of their siblings smoked (Table 2).

\section{Factors associated with tobacco use}

In the bivariate analysis, student's smoking status was found to be significantly associated with year of study, sibling's smoking status and perceived threat to the health. There was no clear trend between year of study and smoking prevalence but those in the preparatory year, $2^{\text {nd }}$ year and fifth year had lower smoking prevalence than the rest. Forty percent of those who had a smoker sibling currently smoked whereas only $17 \%$ of those with a non-smoking sibling currently smoked $(\mathrm{p}=0.001)$. About one-third of those did not think smoking was harmful to health were current smokers as compared to $45 \%$ among those who believed that smoking was harmful $(\mathrm{p}=0.001)$ (Table 3). In binary logistic regression, only sibling's smoking status was found to be significantly associated; students who had a smoking sibling were three times more likely to be current smokers than those without such as sibling $(\mathrm{OR}=2.9,95 \% \mathrm{CI}: 1.4$ to 6.1) (Table 4).

Table 1: Socio-demographic characteristics of the study participants $(N=215)$

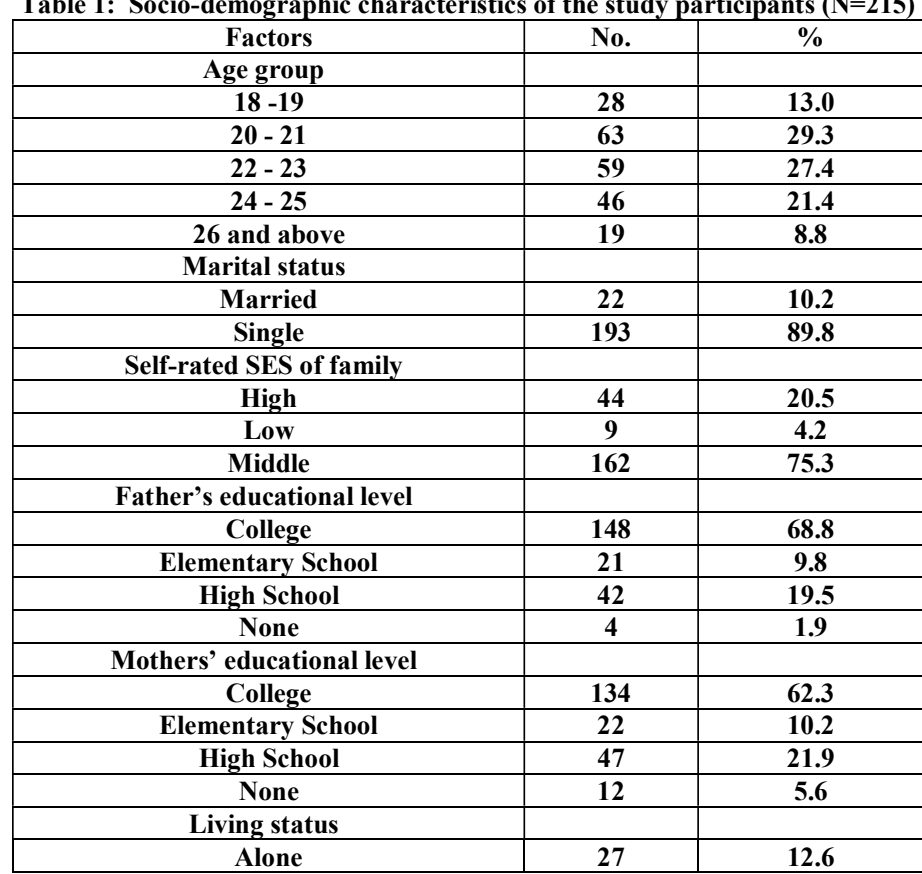




\begin{tabular}{|c|c|c|}
\hline With your family & 188 & 87.4 \\
\hline Year of study & & \\
\hline Prep year & 37 & 17.2 \\
\hline 1st year & 38 & 17.7 \\
\hline 2nd year & 37 & 17.2 \\
\hline 3rd year & 31 & 14.4 \\
\hline 4th year & 39 & 18.1 \\
\hline 5th year & 33 & 15.3 \\
\hline Grade Point Average & & \\
\hline 2.50 or below & 16 & 7.4 \\
\hline $3.50-3.01$ & 56 & 26.0 \\
\hline $4.00-3.51$ & 53 & 24.7 \\
\hline $4.50-4.01$ & 44 & 20.5 \\
\hline $5.00-4.51$ & 46 & 21.4 \\
\hline
\end{tabular}

Table 2: Characteristics of tobacco use among the study participants $(\mathrm{N}=\mathbf{2 1 5})$

\begin{tabular}{|c|c|c|}
\hline Factors & Count & $\%$ \\
\hline $\begin{array}{c}\text { Father smokes } \\
\end{array}$ & 45 & 20.9 \\
\hline Mother smokes & 6 & 2.8 \\
\hline $\begin{array}{c}\text { At least one sibling smokes } \\
\end{array}$ & 51 & 23.7 \\
\hline \multicolumn{3}{|l|}{ For the very first time, got the idea of cigarette smoking from } \\
\hline $\begin{array}{l}\text { Doctors } \\
\end{array}$ & 8 & 3.7 \\
\hline Media & 31 & 14.4 \\
\hline Others & 89 & 41.4 \\
\hline School & 87 & 40.5 \\
\hline \multicolumn{3}{|l|}{ Smoking is harmful to health } \\
\hline Disagree & 3 & 1.4 \\
\hline No Opinion & 4 & 1.9 \\
\hline Slightly Agree & 23 & $\mathbf{1 0 . 7}$ \\
\hline Strongly Agree & 185 & 86.0 \\
\hline Currently use tobacco & 49 & 22.8 \\
\hline \multicolumn{3}{|c|}{ Among those who use tobacco $(\mathrm{N}=49)$} \\
\hline \multicolumn{3}{|c|}{ Form of tobacco use } \\
\hline Chewing/Dipping & 1 & 2.0 \\
\hline Smoking & 48 & 98.0 \\
\hline \multicolumn{3}{|c|}{ Among those who smoke cigarette $(\mathrm{N}=48)$} \\
\hline \multicolumn{3}{|c|}{ Frequency of smoking } \\
\hline A couple of times a month & 5 & 10.4 \\
\hline Daily & 35 & 72.9 \\
\hline Once a week & 1 & 2.1 \\
\hline Three to five times a week & 7 & $\mathbf{1 4 . 6}$ \\
\hline \multicolumn{3}{|l|}{ No. of cigarettes smoked per day } \\
\hline $1-9$ & 24 & $\mathbf{5 0 . 0}$ \\
\hline $10-20$ & 18 & 37.5 \\
\hline $21-30$ & 4 & 8.3 \\
\hline $31-40$ & 2 & 4.2 \\
\hline \multicolumn{3}{|l|}{ Age of initiation of smoking (years) } \\
\hline Below 10 & 1 & 2.1 \\
\hline 11-15 & 8 & 16.7 \\
\hline 16-18 & 23 & 47.9 \\
\hline 19 and above & 16 & 33.3 \\
\hline Thought about quitting tobacco in the past year & 41 & 85.4 \\
\hline
\end{tabular}

Table 3: Bivariate analysis of factors associated with cigarette smoking among the study participants $(\mathrm{N}=\mathbf{2 1 4})$

\begin{tabular}{|c|c|c|c|c|c|c|}
\hline \multirow[t]{3}{*}{ Factors } & \multicolumn{4}{|c|}{ Cigarette smoking } & \multirow{3}{*}{ OR } & \multirow{3}{*}{ P value } \\
\hline & \multicolumn{2}{|c|}{ No } & \multicolumn{2}{|c|}{ Yes } & & \\
\hline & No. & $\%$ & No. & $\%$ & & \\
\hline \multicolumn{7}{|l|}{ Age group } \\
\hline $18-19$ & 23 & 82.1 & 5 & 17.9 & $\mathbf{1 . 0}$ & \multirow[t]{5}{*}{0.50} \\
\hline $20-21$ & 48 & 76.2 & 15 & 23.8 & 1.4 & \\
\hline $22-23$ & 42 & 72.4 & 16 & 27.6 & 1.7 & \\
\hline $24-25$ & 39 & 84.8 & 7 & 15.2 & 0.8 & \\
\hline 26 and above & 14 & 73.7 & 5 & 26.3 & 1.6 & \\
\hline \multicolumn{7}{|l|}{ Living status } \\
\hline Alone & 20 & 74.1 & 7 & 25.9 & 1.0 & \multirow[t]{2}{*}{0.60} \\
\hline With your family & 146 & 78.1 & 41 & 21.9 & 0.8 & \\
\hline
\end{tabular}




\begin{tabular}{|c|c|c|c|c|c|c|}
\hline Year of study & & & & & & \\
\hline Prep year & 30 & 81.1 & 7 & 18.9 & 1.0 & \multirow[t]{6}{*}{0.03} \\
\hline 1st year & 26 & 68.4 & 12 & 31.6 & 2.0 & \\
\hline 2nd year & 32 & 88.9 & 4 & 11.1 & 0.5 & \\
\hline 3rd year & 20 & 64.5 & 11 & 35.5 & 2.4 & \\
\hline 4th year & 28 & 71.8 & 11 & 28.2 & 1.6 & \\
\hline 5th year & 30 & 90.9 & 3 & 9.1 & 0.4 & \\
\hline \multicolumn{7}{|l|}{ Grade Point Average } \\
\hline 2.50 or below & 11 & 68.8 & 5 & 31.3 & 1.0 & \multirow[t]{5}{*}{0.45} \\
\hline 3.50-3.01 & 40 & 71.4 & 16 & 28.6 & 0.9 & \\
\hline $4.00-3.51$ & 41 & 77.4 & 12 & 22.6 & 0.6 & \\
\hline $4.50-4.01$ & 35 & 81.4 & 8 & 18.6 & 0.5 & \\
\hline $5.00-4.51$ & 39 & 84.8 & 7 & 15.2 & 0.4 & \\
\hline \multicolumn{7}{|l|}{ Marital status } \\
\hline Married & 17 & 77.3 & 5 & 22.7 & 1.0 & \multirow[t]{2}{*}{0.90} \\
\hline Single & 149 & 77.6 & 43 & 22.4 & 1.0 & \\
\hline \multicolumn{7}{|l|}{ Self-rated SES of family } \\
\hline High & 34 & 79.1 & 9 & 20.9 & 1.0 & \multirow[t]{3}{*}{0.70} \\
\hline Low & 6 & 66.7 & 3 & 33.3 & 1.9 & \\
\hline $\begin{array}{c}\text { Middle } \\
\end{array}$ & 126 & 77.8 & 36 & 22.2 & 1.1 & \\
\hline \multicolumn{7}{|c|}{ Father's educational level } \\
\hline College & 112 & 76.2 & 35 & 23.8 & 1.0 & \multirow[t]{4}{*}{$\mathbf{0 . 8 0}$} \\
\hline Elementary School & 16 & 76.2 & 5 & 23.8 & $\mathbf{1 . 0}$ & \\
\hline High School & 35 & 83.3 & 7 & 16.7 & 0.6 & \\
\hline None & 3 & 75.0 & 1 & 25.0 & 1.1 & \\
\hline \multicolumn{7}{|c|}{ Mothers' educational level } \\
\hline College & 106 & 79.7 & 27 & 20.3 & 1.0 & \multirow[t]{4}{*}{$\mathbf{0 . 3 0}$} \\
\hline Elementary School & 18 & 81.8 & 4 & 18.2 & 0.9 & \\
\hline High School & 32 & 68.1 & 15 & 31.9 & 1.8 & \\
\hline None & 10 & 83.3 & 2 & 16.7 & 0.8 & \\
\hline Father smokes & 31 & 70.5 & 13 & 29.5 & 1.6 & 0.20 \\
\hline Mother smokes & 3 & $\mathbf{5 0 . 0}$ & 3 & $\mathbf{5 0 . 0}$ & 3.6 & 0.10 \\
\hline Sibling smokes & 30 & 60.0 & 20 & 40.0 & 3.3 & 0.001 \\
\hline \multicolumn{7}{|c|}{ Smoking is harmful to health } \\
\hline Disagree & 2 & 66.7 & 1 & 33.3 & $\mathbf{1 . 0}$ & \multirow[t]{4}{*}{0.001} \\
\hline No Opinion & 2 & $\mathbf{5 0 . 0}$ & 2 & $\mathbf{5 0 . 0}$ & 2.0 & \\
\hline Slightly Agree & 9 & 40.9 & 13 & 59.1 & 2.9 & \\
\hline Strongly Agree & 153 & 82.7 & 32 & $\mathbf{1 7 . 3}$ & 0.4 & \\
\hline
\end{tabular}

Table 4: Binary logistic regression analysis of factors associated with cigarette smoking among the study participants

\begin{tabular}{|c|c|c|c|c|}
\hline & Coefficient & SE & Adjusted odds ratio & P value \\
\hline Year of study & $\mathbf{- 0 . 3 7 4}$ & $\mathbf{0 . 2 4 0}$ & $\mathbf{0 . 6 8}(\mathbf{0 . 4 3 - 1 . 1 0})$ & $\mathbf{0 . 1 1}$ \\
\hline Grade Point Average & $\mathbf{- 0 . 2 8 6}$ & $\mathbf{0 . 1 5 4}$ & $\mathbf{0 . 7 5}(\mathbf{0 . 5 5}-1.01)$ & $\mathbf{0 . 0 6}$ \\
\hline Father smokes & $\mathbf{0 . 4 0 3}$ & $\mathbf{0 . 4 2 3}$ & $\mathbf{1 . 4 9 ( 0 . 6 5 - 3 . 4 2 )}$ & $\mathbf{0 . 3 4}$ \\
\hline Mother smokes & $\mathbf{0 . 8 5 0}$ & $\mathbf{0 . 9 4 6}$ & $\mathbf{2 . 3 4 ( 0 . 3 6 - 1 4 . 9 5 )}$ & 0.36 \\
\hline Sibling smokes & $\mathbf{1 . 0 8 8}$ & $\mathbf{0 . 3 7 1}$ & $\mathbf{2 . 9 6 ( 1 . 4 3 - 6 . 1 4 )}$ & $\mathbf{0 . 0 0 3}$ \\
\hline $\begin{array}{c}\text { Thinks smoking is harmful to } \\
\text { health }\end{array}$ & $\mathbf{- 0 . 9 6 0}$ & $\mathbf{0 . 8 3 5}$ & $\mathbf{0 . 3 8}(\mathbf{0 . 0 7 - 1 . 9 6 )}$ & 0.25 \\
\hline
\end{tabular}

\section{DISCUSSION}

In this study, we found that one-quarter of the medical students were current tobacco users. Majority of the tobacco users were smokers, started smoking at the age of $16-18$ years, smoked daily and 10 or more cigarettes per day. But a majority also thought of quitting tobacco and believed that smoking was harmful to health. About 1 in 5 student's fathers and 1 in 4 student's siblings were current smokers. Only sibling's smoking status was found to be significantly associated with tobacco use among study participants. 
The prevalence found in this study was found to be lower than that reported by many authors. Many authors like Kaabba et al in their study conducted in 2011 in Riyadh found a higher (28.9\%) prevalence of tobacco use among male medical students than the current study. Similar results were obtained by Al Haqwi et al in a study conducted in Riyadh (24\%) in 2010 and Wali et al $(24.8 \%)$ in their study conducted in western Saudi Arabia in 2011.(8-10) Al Turki et al, in central Saudi Arabia, on the other hand, found that the prevalence of tobacco use among male medical students was $13 \%$, which was lower than the current study (11). Subhan MM et al also found lower (14.7\%) prevalence of tobacco use among medical students in a study conducted in Riyadh in 2009 (12). The global health professionals survey conducted in the year 2010 among the third year medical students in Saudi Arabia reported a smoking prevalence of $8.2 \%$ and there was declining trend compared to that reported in 2006 (13, 14). This prevalence was lower than that of the current survey. These differences in prevalence between different studies in Saudi Arabia may be explained partially by provincial differences, differences in year of study and methodological differences.
The global health professionals survey was also conducted among third year male medical students in other middle-eastern countries; according to these surveys the prevalence of smoking was found to be $19.5 \%$ in Yemen (2009), 21.6\% in Bahrain (2009) each, 12.9\% in Egypt (2005), 19.2\% in Kuwait (2010), and less than 1\% in Oman (2010) (15-19). This shows a clear regional difference in the habits of medical students from the different countries.

Most common age at initiation of smoking was found to be 16-18 years in this study. This was found to be similar to that reported by Jarallah et al (20). In the current study, we found that sibling's smoking status was a factor that was significantly associated with cigarette smoking among the medical students. Similarly, this factor was reported by Abdalla et al, who also found that male sex and poor school performance was associated with smoking prevalence.(21) Scholastic performance was not found to be associated with tobacco use in this study. Al Haqwi et al reported that majority of the smokers started using smoking due to peer pressure (8). This was similar to the reported by Wali et al, who also reported that that smoking by parents was also a determinant of smoking by the young professionals.(10) In contrast, we found that the parent's smoking 
status was not related to student's tobacco use. Apart from these factors, many other factors may be involved in determining the tobacco use among young students.

\section{Limitations of the study}

There are several limitations in this study that have to be borne in mind while interpreting the results. This study focused only on the smoking tobacco issues but not other forms of tobacco such as smokeless tobacco or Seesha smoking, which are also prevalent in Saudi Arabia. Apart from the determinants considered here, a number of other factors such as peer pressure, media exposure, mental health issues and academic stress were not considered in this study. Being a cross-sectional study, the temporality of association for the determinants of tobacco use cannot be established here. Only males were included in this study, but in order to get a comprehensive picture of the tobacco use in medical students, female students should also be included in future studies. The results of this study cannot be generalized to all the medical students in Saudi Arabia because it was carried out in only one medical college.

\section{Conclusion and recommendations}

It is clear that smoking is a common risk behavior among the medical students included in the survey and that sibling's have a role to play in influencing the tobacco use behaviors. In order to promote the tobacco control measures in the society and protect the future generation of doctors we need to have a strong tobacco prevention program directed towards the medical students. This is will not only protect their own health but also have an impact on tobacco use by the general population, who will look up to the doctors as role models for emulation. Since medical students may be aware of the harms of tobacco use, a change in the attitudes of the students has to be brought about for effective behavior change (22).

\section{Funding: None}

Conflicts of interest: None declared

Acknowledgements: The authors would like to thank the participants for their time and effort.

\section{REFERENCES}

[1] World Health Organization. Global status report on non-communicable diseases. WHO; Geneva, 2010. http://www.who.int/nmh/publication s/ncd_report_chapter1.pdf

[2] World Health Organization. WHO global report on trends in prevalence of tobacco smoking. Geneva, WHO: 2015.

http://apps.who.int/iris/bitstream/10 
665/156262/1/9789241564922_eng. pdf

[3] Al-Munif MA. Report on Tobacco Control Program of Ministry of Health in Saudi Arabia. Ministry of Health, Saudi Arabia: 2009 Available from: http://www.satcp.com/newsite/user/pdf/REPORT_ ON_TCP.pdf

[4] World Health Organization. Global Health Professional Survey (GHPS). WHO:Geneva.http://www.who.int/t obacco/surveillance/ghps/en/ [Last Accessed on 2017 Aug 14].

[5] Centers for Disease Control and Prevention. Tobacco use and cessation counseling---Global Health Professionals Survey Pilot Study, 10 Countries, 2005. Atlanta, CDC: 2005

[6] World Health Organization. Global Adult Tobacco Survey (GATS). Geneva, WHO.

[7] World Health Organization. Global youth tobacco survey (GYTS). Geneva, WHO.

[8] Al-Haqwi AI, Tamim H, Asery A. Knowledge, attitude and practice of tobacco smoking by medical students in Riyadh, Saudi Arabia.
Ann Thorac Med. 2010; 5(3): 1458.

[9] Al-Kaabba AF, Saeed AA, Abdalla AM, Hassan HA, Mustafa AA. Prevalence and associated factors of cigarette smoking among medical students at King Fahad Medical City in Riyadh of Saudi Arabia. J Fam Community Med. 2011; 18(1): 812.

[10] Wali SO. Smoking habits among medical students in Western Saudi Arabia. Saudi Med J. 2011; 32(8): 843-8.

[11] Al-Turki YA. Smoking habits among medical students in Central Saudi Arabia. Saudi Med J. 2006; 27(5):700-3.

[12] Subhan MM, Al-Khlaiwi T, Ghandourah SO. Smoking among health science university students in Riyadh, Saudi Arabia. Saudi Med J. 2009; 30(12): 1610-2.

[13] WHO Regional office of Eastern Mediterranean Region.Country Fact Sheet- Saudi Arabia, Global Health Professions Student Survey (GHPSS). Geneva, WHO: 2010.

[14] WHO Regional office of Eastern Mediterranean Region.Country Fact Sheet- Saudi Arabia, Global Health 
Professions Student Survey

(GHPSS)Geneva, WHO: 2012.

[15] WHO Regional office of Eastern

Mediterranean Region.Country Fact

Sheet- Yemen, Global Health

Professions Student Survey

(GHPSS)Geneva, WHO: 2010.

[16] WHO Regional office of Eastern

Mediterranean Region. Country Fact

Sheet- Egypt, Global Health

Professions Student Survey

(GHPSS) Geneva, WHO: 2010.

[17] WHO Regional office of Eastern

Mediterranean Region. Country Fact

Sheet- Bahrain, Global Health

Professions Student Survey

(GHPSS) Geneva, WHO: 2010.

[18] WHO Regional office of Eastern

Mediterranean Region. Country Fact

Sheet- Kuwait, Global Health

Professions Student Survey

(GHPSS) Geneva, WHO: 2011.
[19] WHO Regional office of Eastern Mediterranean Region. Country Fact Sheet- Oman, Global Health Professions Student Survey (GHPSS) Geneva, WHO: 2012.

[20] Jarallah JS. Smoking Habits of Medical Students at King Saud University, Riyadh. Saudi Med J. 1992; 13(6): 510-3.

[21] Abdalla AM, Saeed AA, Abdulrahman BM, Al-Kaabba AF, Raat H. Correlates of ever-smoking habit among adolescents in Tabuk, Saudi Arabia. East Mediterr Health J 2009; 15(4): 983-92.

[22] Da Silva LCC, Araújo AJ de, Queiroz ÂMD de, Sales M da PU, Castellano MVC de O, Comissão de Tabagismo da SBPT. Smoking control: challenges and achievements. J Bras Pneumol P 2016; 42(4): 290-8. 